\title{
Nutrigenomics of hepatic steatosis in a feline model: effect of monosodium glutamate, fructose, and Trans-fat feeding
}

\author{
Kate S. Collison - Marya Z. Zaidi · Soad M. Saleh • \\ Nadine J. Makhoul • Angela Inglis · Joey Burrows • \\ Joseph A. Araujo • Futwan A. Al-Mohanna
}

Received: 13 July 2011/Accepted: 19 November 2011/Published online: 6 December 2011

(C) Springer-Verlag 2011

\begin{abstract}
Nonalcoholic fatty liver disease begins with a relatively benign hepatic steatosis, often associated with increased adiposity, but may progress to a more severe nonalcoholic steatohepatitis with inflammation. A subset of these patients develops progressive fibrosis and ultimately cirrhosis. Various dietary components have been shown to contribute to the development of liver disease, including fat, sugars, and neonatal treatment with high doses of monosodium glutamate (MSG). However, rodent models of progressive disease have been disappointing, and alternative animal models of diet-induced liver disease would be desirable, particularly if they contribute to our knowledge of changes in gene expression as a result of dietary manipulation. The domestic cat has previously been shown to be an appropriate model for examining metabolic changes-associated human diseases such as diabetes. Our aim was therefore to compare changes in hepatic gene expression induced by dietary MSG, with that of a diet containing Trans-fat and high fructose corn syrup (HFCS), using a feline model. MSG treatment increased adiposity and promoted hepatic steatosis compared to control $(P<0.05)$. Exposure to Trans-fat and HFCS promoted hepatic fibrosis and markers of liver dysfunction. Affymetrix microarray analysis of hepatic gene expression showed that dietary MSG promoted the expression of genes involved in cholesterol and steroid metabolism.
\end{abstract}

K. S. Collison ( () ) M. Z. Zaidi · S. M. Saleh ·

N. J. Makhoul - A. Inglis - F. A. Al-Mohanna

Cell Biology and Diabetes Research Unit,

Department of Biological and Medical Research, MBC 03,

King Faisal Specialist Hospital and Research Centre,

P. O. Box 3354, Riyadh 11211, Saudi Arabia

e-mail: kate@kfshrc.edu.sa

J. Burrows · J. A. Araujo

VivoCore Inc., Toronto, ON, Canada
Conversely, Trans-fat and HFCS feeding promoted the expression of genes involved in lipolysis, glycolysis, liver damage/regeneration, and fibrosis. Our feline model examining gene-diet interactions (nutrigenomics) demonstrates how dietary MSG, Trans-fat, and HFCS may contribute to the development of hepatic steatosis.

Keywords Hepatic steatosis · Nutrigenomics · High fructose corn syrup (HFCS) · Insulin · Monosodium glutamate (MSG) · Trans-fatty acids (TFA) · Adiposity

$\begin{array}{ll}\text { Abbreviations } \\ \text { ALP } & \text { Alkaline phosphatase } \\ \text { ALT } & \text { Alanine transaminase } \\ \text { B-HBA } & \beta \text {-Hydroxybutyrate } \\ \text { DM } & \text { Diabetes mellitus } \\ \text { MSG } & \text { Monosodium glutamate } \\ \text { HFCS } & \text { High fructose corn syrup } \\ \text { HGF } & \text { Hepatocyte growth factor } \\ \text { TFA } & \text { Trans-fatty acids } \\ \text { NASH } & \text { Nonalcoholic steatohepatitis } \\ \text { NAFLD } & \text { Nonalcoholic fatty liver disease } \\ \text { ROS } & \text { Reactive oxygen species } \\ \text { TAG } & \text { Triglyceride } \\ \text { T-CHOL } & \text { Total cholesterol } \\ \text { HDL } & \text { High-density lipoprotein cholesterol } \\ \text { LDL } & \text { Low-density lipoprotein cholesterol }\end{array}$

\section{Introduction}

Nonalcoholic fatty liver disease (NAFLD), the "hepatic manifestation of the Metabolic Syndrome" consists of a wide spectrum of stages of liver disease ranging from 
simple steatosis to hepatic cirrhosis (Adams and Lindor 2007). NAFLD, characterized by the accumulation of hepatic triacylglycerol (TAG) is frequently accompanied by obesity (Youssef and McCullough 2002), and hepatic steatosis is prevalent in approximately $17 \%$ of lean individuals and up to $70 \%$ of obese persons (Bellentani et al. 2000). A proportion of patients go on to develop nonalcoholic steatohepatitis (NASH), characterized by inflammation and fibrosis; however, the risk factors that precipitate the progression from NAFLD to NASH remain incompletely understood (Wouters et al. 2008), and the mechanism of progression from simple steatosis to a more severe pathology is still the subject of intense research activity. Several dietary macronutrients have been proposed to play a role in the development of hepatic steatosis (Lê and Bortolotti 2008), in particular a diet enriched with Trans-fat and a high fructose corn syrup (HFCS) equivalent was shown to promote severe NAFLD and hepatic necroinflammatory changes in rodents (Tetri et al. 2008). Additionally, we have shown that Trans-fat (Collison et al. 2009a) and HFCS (Collison et al. 2010) alter rodent hepatic and white adipose tissue gene expression, promoting upregulation of lipogenic gene transcription and the deposition of hepatic TAG. The majority of research into the etiology and pathophysiology of hepatic steatosis has been performed using small animal models; however, rodent models of progressive diet-induced liver disease have been disappointing for a number of reasons (Larter and Yeh 2008; Anstee and Goldin 2006; Ogasawara et al. 2011), and there is still a need for additional models that may contribute to our knowledge of the factors associated with the development of hepatic fibrosis and more severe associated pathology. Alternative animal models examining the effects of dietary components on the development steatosis and fibrosis would be advantageous particularly if they contribute to our knowledge of changes in gene expression as a result of dietary manipulation.

The domestic cat has previously been shown to be an appropriate model for examining metabolic changes-associated human diseases such as diabetes (Hoenig 2006; Henson and O'Brien 2006). Hepatic steatosis in the cat can occur as a result of simple obesity or during weight loss/ starvation resulting in lipid mobilization to the liver (Ibrahim et al. 2003). Obesity is a risk factor for feline diabetes (Henson and O'Brien 2006) and feline hepatic steatosis (Crystal and Norsworthy 2007); and as with humans, overweight cats are becoming increasingly prevalent (German 2006). Further similarities between feline and human diabetes include the development of insulin resistance, hyperglycemia, and pancreatic Islet cell lesions, together with partial loss of pancreatic $\beta$ cells (Adams and Lindor 2007; Hoenig 2002). In light of these similarities, cats have been proposed as an excellent model for the study of mammalian obesity and diabetes (Henson and O'Brien 2006). However, despite these similarities, much less is known about the feline response to dietary manipulation, particularly its effect on feline hepatic steatosis, and more information would be desirable if the feline model is to be pursued as a viable alternative to the use of rodents in this respect.

Adulthood obesity can also be induced by neonatal treatment with monosodium glutamate (MSG) (Hermanussen and Tresguerres 2003; Alponti et al. 2011; RomanRamos et al. 2011; Hirata et al. 1997; Diniz et al. 2005), a commonly consumed food flavor enhancer that frequently occurs in so-called Western-style diets containing both Trans-fats and/or HFCS. In this well-characterized rodent model, MSG administered orally during the neonatal period has been shown to result in hyperinsulinemia and obesity (Hermanussen and Tresguerres 2003; Alponti et al. 2011; Roman-Ramos et al. 2011; Hirata et al. 1997; Diniz et al. 2005). Additionally, subcutaneous injections of MSG given to infant mice results in liver changes similar to human NAFLD (Sasaki et al. 2009; Nakanishi et al. 2008). The mechanism behind this is believed to involve glutamate-induced degeneration of those areas of the immature brain, which are insufficiently protected by a mature blood-brain barrier, including regions that regulate feeding and energy metabolism (Hermanussen and Tresguerres 2003; Diniz et al. 2005; Minor et al. 2011). Interestingly, MSG-induced hypothalamic obesity is not accompanied by hyperphagia. Rather, the increased adiposity appears to be due to hormonal imbalance resulting in hyperinsulinemia together with growth hormone perturbations and atrophied pituitary glands (Hermanussen and Tresguerres 2003; Alponti et al. 2011; Roman-Ramos et al. 2011; Hirata et al. 1997; Diniz et al. 2005; Minor et al. 2011; Matyšková 2008). Given the fact that maternal oral administration of MSG can result in detectable levels of glutamic acid accumulation in the fetal brain (Hermanussen and Tresguerres 2003; Nemeroff et al. 1978), and that in rodents, the hepatotoxic effects of MSG may also be apparent even when administered orally (Yu et al. 1997), it would be of interest to ascertain the effects of neonatal administration of dietary MSG in a higher animal model. It has previously been shown that intravenous injections of MSG promote the development of hypothalamic lesions in young cats (Tanaka et al. 1983); and we have previously shown that whereas neonatal exposure to MSG promotes a phenotype of increased feline adiposity and reduced insulin sensitivity, Trans-fat and HFCS feeding results in an apparent elevation in cortisol and markers of liver dysfunction (Collison et al. 2011). The present study seeks to further investigate the effect of Trans-fat, HFCS, and/or MSG on feline hepatic steatosis and gene expression.

Although feline microarrays are not yet available, the use of human microarrays for the examination of feline 
gene expression has previously been validated by Dowling and Bienzle (Dowling and Bienzle 2005), who noted that feline genes generally have $>85 \%$ sequence similarity to their human counterparts (Dowling and Bienzle 2005; Nishimura et al. 1998; Ritchey et al. 2001). Our goal therefore was to compared the effects of four isocaloric diets on feline hepatic histology and gene expression, using a combination of partially hydrogenated vegetable shortening (PHVS) and HFCS to generate a Trans-fat (9\%), HFCS (24\%) diet. The effect of this diet was compared to an isocaloric standard chow, either in the presence or absence of dietary MSG (1.125\%), in a model that we have previously established in rodents (Collison et al. 2009a, 2010), and more recently in cats (Collison et al. 2011). We bred our study animals from female cats who were previously established on these separate diets for 3 weeks prior to mating, since some of the effects of MSG are believed to occur only during the neonatal period (Alponti et al. 2011; Roman-Ramos et al. 2011; Hirata et al. 1997; Diniz et al. 2005; Matyšková 2008; Nemeroff et al. 1978; Yu et al. 1997), and because developmental programming of the metabolic syndrome may be affected by maternal nutritional balance (Armitage et al. 2004; De Campos et al. 2007).

\section{Experimental procedures}

\section{Animals and diets}

The breeding and care of the animals were in accordance with the protocols approved by the Animal Care and Use Committee of the King Faisal Specialist Hospital \& Research Centre and by the Institutional Animal Care Committee of Guelph University with guidelines set forth by the Canadian Council on Animal Care. A total of 8 female domestic cats were used to breed the 18 male subjects used in this study, as previously described (Collison et al. 2011). Briefly, heating and cooling were electronically controlled and were set to maintain the room in a temperature range from 18 to $25^{\circ} \mathrm{C}$. The room ventilation was designed to provide approximately 15 filtered air changes per hour. Pen allocations for the cats provided each cat with a minimum of 0.56 square meters of personal space. All animals were routinely examined by a veterinarian at regular intervals throughout the study. Four isocaloric formulated feline diets manufactured by Test Diet Purina, Purina Mills, USA, were used in this study: [1] Control Laboratory Feline Diet (Control: catalog \#5003). [2] MSG diet consisting of Control laboratory Feline Diet with $1.125 \%$ added monosodium glutamate (Diet A: cata$\log$ \#5C1J). [3] Trans-fat/HFCS diet, consisting of a control diet with added $8.6 \%$ Trans-fat and 24\% HFCS (Diet B: catalog \#5B4K). [4] Trans-fat/HFCS and MSG diet,
Table 1 Diet composition

\begin{tabular}{lrrrr}
\hline & Control & Diet A & Diet B & Diet C \\
\hline Protein (\%) & 31.50 & 30.70 & 31.50 & 31.50 \\
Fat (\%) & 11.50 & 12.10 & 19.00 & 19.00 \\
TFA (\%) & 0.32 & 0.32 & 6.65 & 6.65 \\
Carbohydrate (\%) & 37.00 & 38.40 & 30.10 & 30.20 \\
Fructose (\%) & 0.13 & 0.13 & 13.12 & 13.12 \\
Glucose (\%) & 0.13 & 0.13 & 10.82 & 10.82 \\
Fiber (\%) & 2.50 & 2.30 & 1.40 & 1.40 \\
MSG (\%) & 0.00 & 1.13 & 0.00 & 1.13 \\
Energy (Kcal/g) & 4.04 & 3.95 & 4.17 & 4.17 \\
\hline
\end{tabular}

consisting of a control diet with added $8.6 \%$ Trans-fat, 24\% HFCS and $1.125 \%$ MSG (Diet C: catalog \#5C1H). See Table 1 for diet composition. All diets contained approximately $30 \%$ animal-based protein and $0.2 \%$ taurine. Detailed descriptions of the ingredients in these diets are listed, by catalog number, with the manufacturer (http:// www.testdiet.com). The cats were fed twice a day for about an hour and were fed to meet their maintenance energy requirements (MER) estimated by the formula "MER = $110 \mathrm{cal} /$ day $\times($ BW0.75)" (Laflamme 2007). Average MSG consumption as part of the diet $\mathrm{A}$ and $\mathrm{C}$ was $201.4 \pm$ $18.65 \mathrm{mg} / \mathrm{Kg}$ body weight. A preliminary diet acceptability study was performed on the breeder animals over a period of 1 week, to ascertain that the diets were palatable, as previously described (Collison et al. 2011). Food consumption was monitored at every feed, and body weight was recorded at the beginning and end of the acceptability study. 2 female breeders per diet group were established on each of the four different diets for 3 weeks prior to mating, and the pregnant females continued on these diets throughout the gestation and weaning period. The male offspring from these four diet groups continued to consume their respective diets throughout the length of the study. Percentage body fat in the study subjects was assessed at 9 months of age by dual energy X-ray absorptiometry (DEXA) using the Lunar DPX-IQ densitometer (http:// www.gehealthcare.com Lunar Corp., Madison, WI), as previously described (Collison et al. 2011).

Biochemical measurements

Serum lipids, alkaline phosphatase (ALP), alanine transaminase (ALT), $\beta$-hydroxybutyrate (B-HBA), fasting serum insulin, and glucose were assessed at 9 months of age as previously described (Collison et al. 2011). Briefly, a minimum of $3 \mathrm{ml}$ of blood was collected from overnight fasted cats by venipuncture from either the jugular, cephalic, or saphenous veins using standard restraint techniques. Blood tubes were placed on ice and transported the same day to the 
reference laboratory (Advanced Vet Labs, Mississauga, Canada) for analysis. Additionally, serum samples were obtained at necropsy and frozen at $-80^{\circ} \mathrm{C}$. Serum TAG, T-CHOL, LDL-C, and HDL-C concentrations were measured in 9-month-old fasted cat serum using the Reflovet plus Instrument (Roche, F. Hofmann-La-Roche Ltd, Basel, Switzerland), according to the manufacturer's instructions. Fasting serum insulin was measured using the feline insulin ELISA kit from Mercodia (catalog 10-1233-01). Homeostatic Model Assessment Index (HOMA-IR) values, a measure of insulin resistance, were calculated according to the established formula: (fasting serum insulin $\mu \mathrm{IU} / \mathrm{ml}) \times$ (fasting serum glucose mM)/22.5 (Matthews et al. 1985).

Liver histology and hepatic triacylglycerol (TAG) quantitation

At 9 months of age, animals were humanely euthanized formalin-fixed, paraffin-embedded liver sections from 9-month-old animals were processed, and $4 \mu \mathrm{m}$ thick serial sections were cut and stained with Masson's Trichrome stain using standard laboratory protocols. Levels of hepatic TAG were quantified from snap-frozen tissue using the Triglyceride Determination Kit TRO100 with appropriate triacylglycerol standards (Sigma Aldrich, MO, USA) as described previously (Collison et al. 2009a, 2010).

\section{Hepatic RNA isolation}

Total RNA was prepared from snap-frozen liver tissue using Qiagen RNeasy Kit (Qiagen, USA) according to the manufacturer's instructions and stored at $-80^{\circ} \mathrm{C}$. RNA quality was verified using a 2100 Bioanalyzer instrument and an RNA 6000 Nano LabChip assay (Agilent Technologies, Palo Alto, CA). RNA concentrations were determined by absorption at $260 \mathrm{~nm}$ wavelength with an ND-1000 spectrometer (Nanodrop Technologies, Wilmington, DE).

\section{Microarray hybridization}

Gene expression in 18 liver samples was analyzed using 8 GeneChip (R) Human Gene 1.0 ST arrays representing 28,869 genes (http://www.affymetrix.com). We used 2 chips per diet group and applied pooled hepatic RNA from four to five cats per chip in duplicate. Targets were prepared, and microarrays were processed as described in the Affymetrix GeneChip Whole Transcript Expression Analysis manual using commercially available Affymetrix GeneChip WT cDNA Synthesis Kit, WT cDNA Amplification Kit, and WT Terminal Labeling Kit as per manufacturer's instructions. Briefly, approximately $300 \mathrm{ng}$ of total RNA was used to synthesize double-stranded DNA with random hexamers tagged with a $\mathrm{T} 7$ promoter sequence. The cDNA was used as a template for in vitro transcription. In the second cycle cDNA synthesis, random primers were used in reverse transcription to convert the cRNA into single-stranded DNA, which was fragmented, labeled, and hybridized to the array for $17 \mathrm{~h}$ using the Fluidics 450 station. Arrays were scanned using the Affymetrix $30007 \mathrm{G}$ scanner and GeneChip Operating Software version 1.4 to produce. CEL intensity files. Array QA metrics were evaluated using the Affymetrix Expression Console software. This software also provided summary reports by which array QA metrics were evaluated including average background, average signal, and $3^{\prime} / 5^{\prime}$ expression ratios for spike-in controls, $\beta$-actin, and GAPDH.

Expression array analysis

Microarray expression analysis was performed using the Partek genomic suite software version 6.3 (http://www. Partek.com, MO, USA). Probeset data were background adjusted and quantile normalized using the GC-Robust Multi-Array (GCRMA) algorithm. This normalization method is used to reduce discrepancies in hybridization patterns that might result from variables in target amplification, hybridization conditions, staining, or probe array lot. After normalization and elimination of variance based on noise at low expression levels, probesets were culled for redundancy where there were multiple probesets per gene. Statistically significant differences among the diet groups were identified using ANOVA. A false discovery rate (FDR) of 5\% was applied. Probesets that satisfied the criterion of a $P$ value $\leq 0.01$ and a fold change $\geq 1.5$ were considered to be significantly regulated for the post hoc comparisons diet A versus control, diet B versus control, and diet $C$ versus diet $B$. The data were submitted to NCBI gene expression and hybridization array data repository (GEO, http://www.ncbi.nlm.nih.gov/geo/) under accession number GSE30040.

Interaction network and pathway analysis

Ingenuity Pathway Analysis (IPA) software (http://www. ingenuity.com, version 8.7; Ingenuity Systems, Redwood, CA) was utilized to determine the function ontology, possible biological pathways, and intermolecular networks between candidate genes that were differentially expressed in the liver by the various dietary regimens. Gene function ontology analysis identified the biological functions most significant to the data set. Right-tailed Fisher's exact test was used to calculate significance calculated for each function returned in the biological functional analysis. Genes in the data set were overlaid onto a global molecular network developed from information contained in the Ingenuity Knowledge Base. Networks of eligible biologically related 
genes were algorithmically generated based on their connectivity. The functional analysis of a network identified the biological functions and/or diseases that were most significant to the molecules in the network. In the networks created, each node represents a molecule and the biological relationships between them are depicted as lines. All relationships are based on information stored in the Ingenuity Knowledge Base, supported by at least 1 reference from the literature.

Real-time PCR quantification

Confirmation of microarray results was performed using quantitative real-time RT-PCR (qRT-PCR) of 10 of the significant differentially regulated genes for which the Felis catus mRNA sequence has been published (Table 2). Genespecific primers corresponding to the PCR targets were designed using primer 3 software available online. Preliminary real-time RT-PCR experiments were performed with each primer pair to determine the annealing temperature that yielded the greatest amount of specific product with melting temperature (Tm) separable from primer dimer Tm. Standard curves were prepared for each run using known quantities of cDNA as described previously (Collison et al. 2009a, 2010). Relative quantitation measurements were taken using external standard curves for both target and $\beta$-actin housekeeping gene. The 2 nd derivative maximum method was used for ct calculation from amplification curves. The respective concentration for any given sample was calculated using crossing-cycle analysis provided by the
LightCycler software. Real-time RT-PCR values for each target gene were calculated as a ratio of target gene expression level to the $\beta$-actin expression level in the same specimen. For comparisons with the microarray data, these values were then expressed as mean percentage \pm SEM of real-time RT-PCR levels in the control diet group. Ratios of expressions among the diet comparisons and Pearson correlation coefficients $(r)$ between the microarray data and the felis cattus RT-PCR data were calculated to determine concordance between them.

Statistical analysis

All analysis was performed using the software SPSS (Version 13.0, SPSS Inc, Chicago, USA) and GraphPad InStat version 3 (CA, USA). Data are presented as mean$\mathrm{s} \pm$ SEM of body fat, clinical chemistry, serum lipid profile, and hormone measurements as previously described (Nemeroff et al. 1978). Data were analyzed by one-way ANOVA with Bonferroni's post hoc tests to determine statistically significant difference between selected diet groups. Significance was set at $P<0.05$.

\section{Results}

Liver histology and body characteristics induced by diet

There was no significant difference in the averaged food intake and body weights between animals in the four dietary

Table 2 Primers list for qRT-PCR

\begin{tabular}{|c|c|c|c|c|}
\hline Name & Symbol & $\begin{array}{l}\text { Accession } \\
\#\end{array}$ & Forward primer & Reverse primer \\
\hline ATP citrate lyase & ACLY & GU332841 & 5'AGACCAGAAGGGAGTGACCAT3' & 5'TGGTCCGAGAGATGATATTGT3' \\
\hline Fatty acid synthase & FASN & AB436620 & 5'TGCTGCTGAGCACAGACGAG3' & 5'GCACCTCCTTGGCAAACACA3' \\
\hline $\begin{array}{l}\text { Glutathione S-transferase mu } 3 \\
\text { (brain) }\end{array}$ & GSTM3 & AY672094 & 5'GATTCGAGTGGACATCATGG3' & 5'TCATAGGTGAGGAAATCCACAA3 \\
\hline Erythropoietin & EPO & L10606 & 5'AATATCACTGTCCCAGACACCAA3' & 5'TGGCTTCCTTCTGGGCTC $3^{\prime}$ \\
\hline Von Willebrand factor & VWF & U31613 & 5'GCTGTCCGAGGCTGAGTT3' & 5'TTCAAGACCTCGCTGGTGGA3' \\
\hline $\begin{array}{l}\text { Glucose-6-phosphatase, } \\
\text { catalytic subunit }\end{array}$ & G6PC & DQ525410 & 5'ACTTTGGGATCCAGTCAACG3' & 5'GAGTTTGATGCCCACAGCTT3' \\
\hline $\begin{array}{l}\text { Hepatocyte growth factor } \\
\text { (hepapoietin A; scatter } \\
\text { factor) }\end{array}$ & HGF & AB080187 & 5'TCGTTGTGAAGGTGATACCA3' & 5'TCCTTTATCAATGATCCTCC3' \\
\hline $\begin{array}{l}\text { V-fos FBJ murine } \\
\text { osteosarcoma viral oncogene } \\
\text { homolog }\end{array}$ & FOS & AF540379 & 5'CGAAGGGAAAGGAATAAGAT3' & 5'GCTGCCAGGATGAACTCTAGT3' \\
\hline $\begin{array}{l}\text { ATP-binding cassette, } \\
\text { subfamily B (MDR/TAP), } \\
\text { member } 1\end{array}$ & $\mathrm{ABCB} 1$ & AB029153 & 5'TGGTTGGAAGCTAACCCTTG3' & 5'TTTGTCCTCCAAAGGCAATC3' \\
\hline $\begin{array}{l}\text { V-myc myelocytomatosis viral } \\
\text { oncogene homolog }\end{array}$ & MYC & FJ775539 & 5'CTCTGCTCGCCCTCCTACGTC3' & 5'TCCTGCAGGTACAAGCTGGA3' \\
\hline
\end{tabular}


groups (Table 3). The livers from MSG diet group A cats had the appearance of increased steatosis (Fig. 1a, b), which was reflected in a significant elevation in hepatic TAG content (Fig. 1c, $P<0.05$ ). Conversely, the liver tissue from Transfat/HFCS diet B and C animals showed fibrous expansion of several portal areas with occasional portal-to-portal bridging, as indicated by Masson's Trichrome-stained liver sections (Fig. 1a, b). The combination of Trans-fat/HFCS and MSG (diet C) resulted in an increase in hepatic TAG content compared to Trans-fat/HFCS alone (Fig. 1c, $P<0.05$ ). Despite the fact that there was no significant difference in the amount of food consumed (data not shown), total body fat was significantly higher in the diet A cats compared to animals on diets $\mathrm{B}$ and $\mathrm{C}$ (Table $3, P<0.05$ ). Fasting insulin and HOMA-IR values in diet group A cats were at least 2.4fold higher than control and diet $\mathrm{C}$ groups, suggesting the development of insulin resistance in diet $\mathrm{A}$ animals (Table 3 , $P<0.05)$. diet group B animals had twice the levels of serum alkaline phosphatase (ALP) and alanine transaminase (ALT) than animals in Group $\mathrm{C}(P<0.001)$, suggesting impairment of liver function in these cats. diet $\mathrm{B}$ animals also had the highest levels of serum creatinine $(P<0.01)$. Additionally, serum cortisol levels were elevated in both diet groups $\mathrm{B}$ and $\mathrm{C}(P<0.0001)$.

Effect of the Trans-fat/HFCS diet on feline hepatic gene expression

In order to identify the subset of hepatic genes with a fold difference of \pm 1.5 or more for comparisons of cats fed the
Trans-fat/HFCS diet versus control, we used the results from a 2-way ANOVA model described in the methods section and considered only the genes with a significance of $P<0.01$. We identified 1829 differentially expressed genes (DEGs:1078 upregulated and 751 downregulated) that were modulated by Trans-fat/HFCS. Figure 2 shows diet-induced modification of the expression of selected genes involved in lipid and carbohydrate metabolism, liver damage/regeneration, fibrosis, angiogenesis, and inflammation. Livers from Trans-fat/HFCS diet group B cats exhibited reduced expression of lipogenic DEGs including SREBF1, fatty acid synthase (FAS), and ATP citrate lyase (ACLY) all of which were attenuated by approx fourfold compared to control $(P<0.05)$. This diet also decreased the expression of hepatic DEGs involved in cholesterol excretion such as the ATP-binding cassette transporters ABCG8 (2.1-fold) and ABCC3 (14-fold), and the ratelimiting enzyme in bile acid biosynthesis CYP7A1 (5.3fold). Levels of hydroxy-3-methylglutaryl-CoA reductase (HMGCR), the rate-limiting enzyme for de novo cholesterol biosynthesis was reduced 4.7-fold; additionally, levels of HDL receptor and Apolipoprotein B were reduced by 3.7- and 2-fold, respectively, in diet B animals. Conversely, this diet upregulated the expression of lipolytic PPARD (1.8-fold) together with a number of DEGs involved in $\beta$-oxidation of fats including acyl-CoA synthetases (ACSF2 :1.9-fold; ACSL6: 1.6-fold, ACSBG2: 1.6-fold). The expression of genes participating in glycolysis and fructolysis was also upregulated by Trans-fat/HFCS feeding compared to control, including hexokinase, aldolase A

Table 3 Body fat, hormones, clinical chemistry, and lipid profile in cats

\begin{tabular}{|c|c|c|c|c|c|}
\hline & Control & Diet A & Diet B & Diet $\mathrm{C}$ & $P$ value \\
\hline Food intake $(\mathrm{g})$ & $79.56 \pm 4.66$ & $77.50 \pm 6.44$ & $62.72 \pm 3.11$ & $67.72 \pm 5.77$ & 0.14 \\
\hline Body weight (kg) & $4.06 \pm 0.13$ & $4.38 \pm 0.15$ & $3.24 \pm 0.17$ & $3.75 \pm 0.57$ & 0.09 \\
\hline Total body fat (\%) & $20.85 \pm 1.26^{\mathrm{ab}}$ & $27.06 \pm 3.09^{b}$ & $16.20 \pm 0.97^{\mathrm{a}}$ & $16.70 \pm 2.05^{\mathrm{a}}$ & 0.01 \\
\hline Fasting glucose $\mathrm{mM}$ & $4.00 \pm 0.14$ & $5.33 \pm 0.56$ & $5.18 \pm 0.23$ & $5.12 \pm 0.44$ & 0.21 \\
\hline Fasting insulin $\mu \mathrm{U} / \mathrm{ml}$ & $8.00 \pm 2.11^{\mathrm{a}}$ & $19.88 \pm 2.81^{\mathrm{b}}$ & $14.54 \pm 5.74^{\mathrm{ab}}$ & $4.96 \pm 1.33^{\mathrm{a}}$ & 0.02 \\
\hline HOMA-IR & $1.41 \pm 0.37^{\mathrm{a}}$ & $4.39 \pm 0.24^{\mathrm{b}}$ & $3.20 \pm 1.12^{\mathrm{ab}}$ & $1.15 \pm 0.31^{\mathrm{a}}$ & $<.01$ \\
\hline ALP (U/L) & $93.40 \pm 6.45^{\mathrm{ab}}$ & $70.40 \pm 7.36^{\mathrm{a}}$ & $120.75 \pm 15.61^{\mathrm{b}}$ & $55.50 \pm 7.14^{\mathrm{a}}$ & 0.001 \\
\hline ALT (U/L) & $79.60 \pm 12.13^{\mathrm{ab}}$ & $55.60 \pm 2.2^{\mathrm{a}}$ & $102.00 \pm 13.51^{\mathrm{b}}$ & $50.25 \pm 6.47^{\mathrm{a}}$ & 0.01 \\
\hline Creatinine $(\mu \mathrm{mol} / \mathrm{l})$ & $90.40 \pm 7.83^{\mathrm{a}}$ & $108.60 \pm 6.05^{\mathrm{ac}}$ & $138.50 \pm 5.85^{\mathrm{b}}$ & $128.00 \pm 5.81^{\mathrm{bc}}$ & $<.001$ \\
\hline Cortisol (ng/ml) & $32.82 \pm 1.83^{\mathrm{a}}$ & $35.29 \pm 1.69^{\mathrm{a}}$ & $45.86 \pm 1.51^{\mathrm{b}}$ & $49.82 \pm 1.72^{\mathrm{b}}$ & $<.0001$ \\
\hline B-HBA $(\mu \mathrm{mol} / \mathrm{l})$ & $22.60 \pm 8.24^{\mathrm{a}}$ & $31.80 \pm 7.53^{\mathrm{ab}}$ & $48.25 \pm 12.45^{\mathrm{ab}}$ & $62.00 \pm 7.6^{\mathrm{b}}$ & 0.04 \\
\hline Leptin (ng/ml) & $4.50 \pm 0.53^{\mathrm{ab}}$ & $5.29 \pm 1.34^{\mathrm{b}}$ & $1.09 \pm 0.42^{\mathrm{c}}$ & $0.58 \pm 0.09^{\mathrm{c}}$ & 0.001 \\
\hline Serum T-CHOL $(\mu \mathrm{g} / \mathrm{ml})$ & $162.80 \pm 9.44$ & $154.60 \pm 11.48$ & $147.25 \pm 7.86$ & $162.25 \pm 9.39$ & 0.68 \\
\hline Serum HDL $(\mu \mathrm{g} / \mathrm{ml})$ & $82.94 \pm 7.21$ & $93.70 \pm 4.57$ & $76.10 \pm 7.92$ & $88.65 \pm 6.44$ & 0.31 \\
\hline Serum LDL $(\mu \mathrm{g} / \mathrm{ml})$ & $51.05 \pm 6.82$ & $44.42 \pm 11.99$ & $51.08 \pm 3.51$ & $51.54 \pm 5.61$ & 0.91 \\
\hline Serum TG $(\mathrm{mmol} / \mathrm{l})$ & $0.94 \pm 0.17$ & $1.26 \pm 0.29$ & $0.65 \pm 0.16$ & $0.54 \pm 0.04$ & 0.09 \\
\hline
\end{tabular}

Results are mean \pm SEM

Statistical significance for difference in means at $P$ value $<0.05$ is denoted by different letters $a b c$ for the comparisons of control and diet $\mathrm{C}$ with diet $\mathrm{A}$ and $\operatorname{diet} \mathrm{B}$ 
A

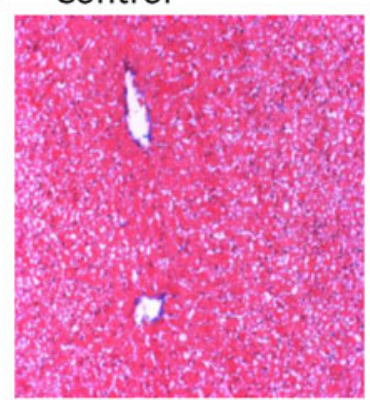

B

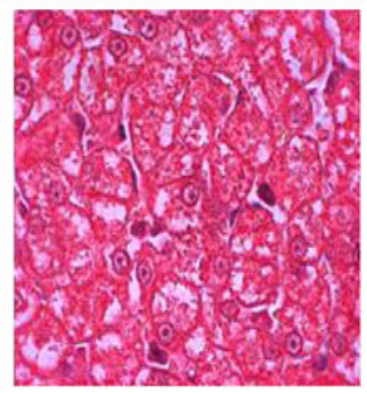

Diet A
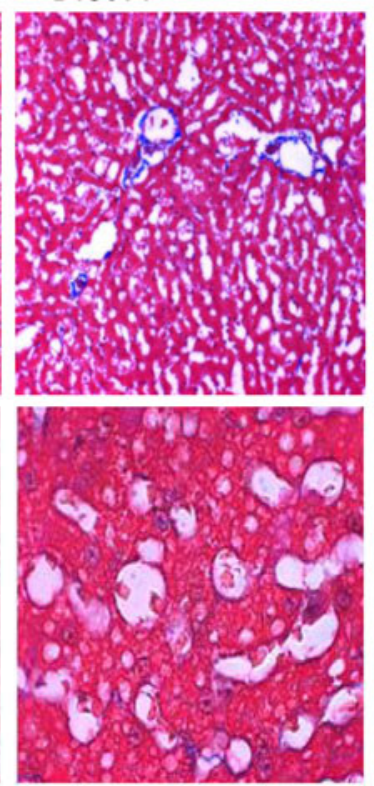

Diet B
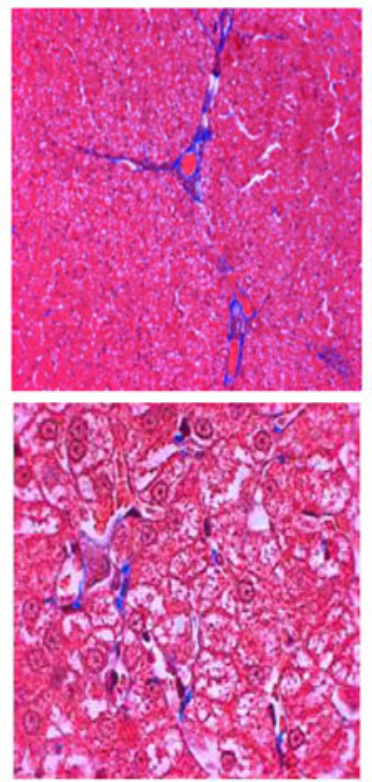

Diet C
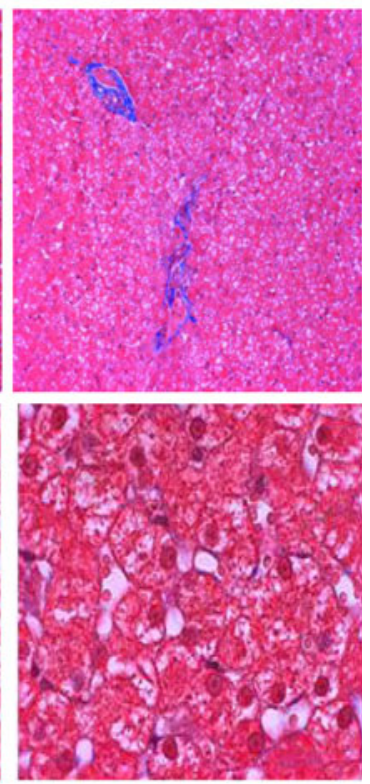

C

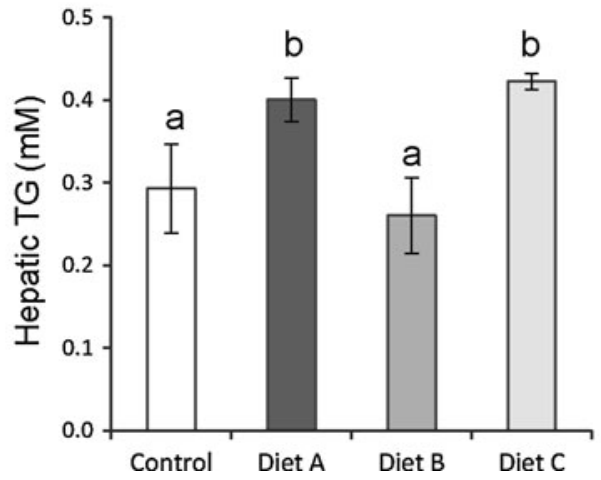

Fig. 1 Effect of diet on hepatic morphology and triacylglycerol content. a Micrographs of hepatic tissue from control cats and those in diet group $A, B$, and $C$. Magnification is $10 \times$; results are representative of at least 4 animals per diet group. b Higher magnification

(both 2.8-fold), phosphoglycerate mutase PGAM2 and PGAM5 (2 and 1.5-fold, respectively), together with the facilitated glucose transporter SLC2A13 (1.7-fold). diet B also upregulate several genes that have been associated with liver damage/regeneration including glypican-3 (1.6fold), heparan sulfate proteoglycan 2 (Perlecan; 5.3-fold), cytochrome $\mathrm{c}$ (7.2-fold), and a threefold rise in the expression of glutathione $S$ transferases 1, 4 and 5 (Fig. 4, $P<0.05)$. In addition to the histological evidence that suggested increased hepatic fibrosis in diet group B cats, several collagen genes (for example, Col4a4, Col 5a3, Col6a2, Col6a3, and nine other collagen isoforms) were upregulated by approximately 2.5 -fold in this diet group, together with a marked elevation in the expression of fibrosis-associated Synoviolin (Fig. 4). Fibroblast growth factors (Fgf1 and Fgf20) were also elevated by 1.8-2.5-fold
$(100 \times)$ images show the differences in hepatic morphology induced by the diets. c Hepatic TAG content per diet group (mean \pm SEM, $P<0.05)$

in these cats $(P<0.05)$. Also promoted the expression of genes involved in angiogenesis, including hepatocyte growth factor (HGF, 1.5-fold), urokinase plasminogen activator (uPA, 3-fold) and sirtulin 1 (SIRT1, 3-fold). Evidence for the involvement of an inflammatory response to the Trans-fat/HFCS diet is shown by a fivefold upregulation of interleukin 2 (IL-2: 4-fold), Macrophage Scavenger Receptor 1 (MSR1, 5.5-fold) and chemokine (C-C motif) receptor 1 (CCR1, 5-fold). Figure 2 also shows that this diet upregulated genes involved in cell proliferation, such as the key proliferation marker proliferating cell nuclear antigen (PCNA; 4-fold), Indian hedgehog homolog (IHH, 1.9-fold), and anti-apoptotic X-linked inhibitor of apoptosis (XIAP; 5.7-fold). Additionally, the diet B increased the expression of several DEGs previously identified as upregulated in hepatocellular carcinoma 


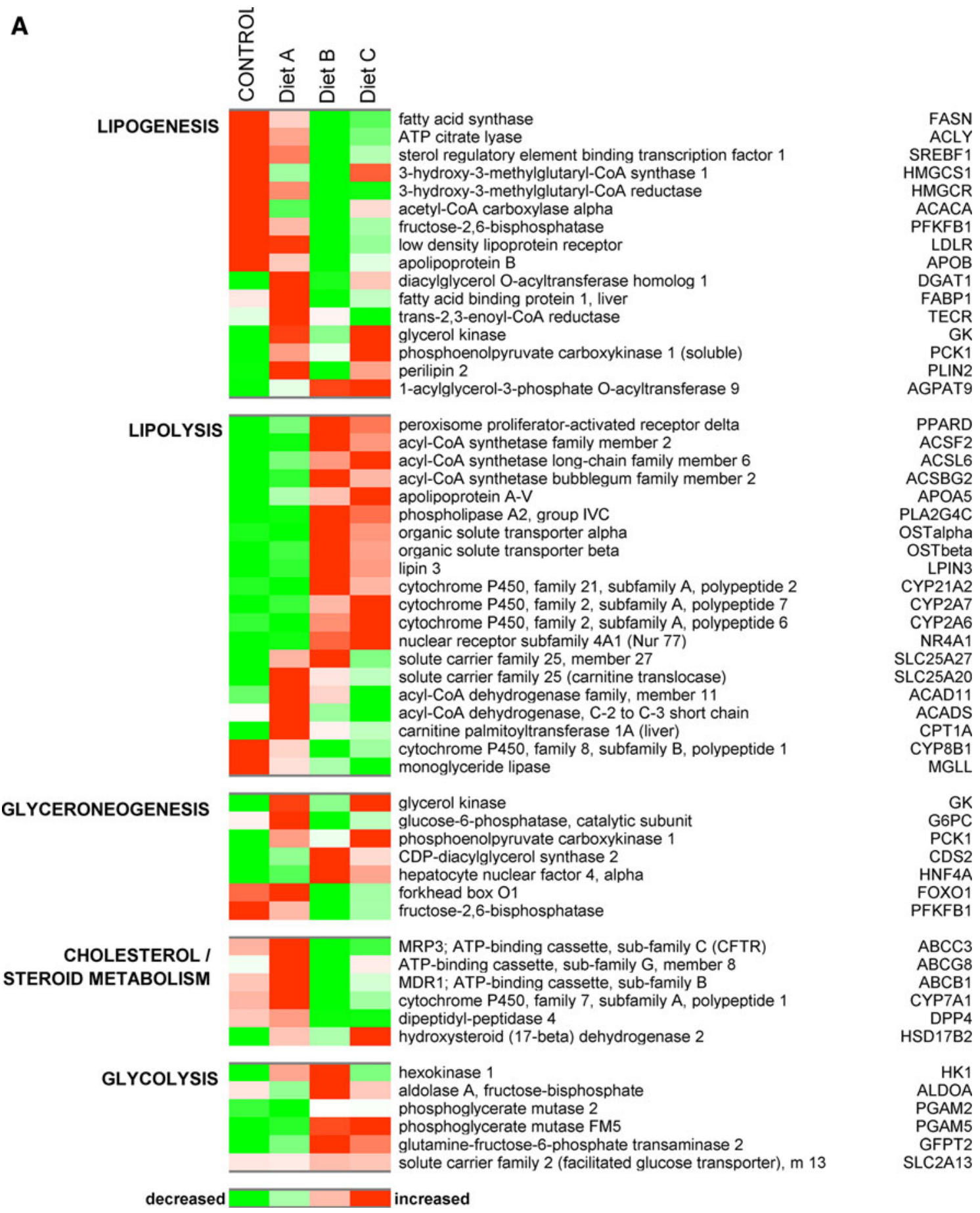

Fig. 2 a Heatmap depicts the effect of dietary manipulation on the expression of genes involved in lipogenesis, lipolysis, gluconeogenesis, and glycolysis. Heatmap shows genes represented horizontally, and diet groups represented by the vertical rows: red color signals genes with increased expression while green indicated a reduction in

(HCC) including v-rel reticuloendotheliosis viral oncogene homolog A (RelA, 3-fold), metastasis-associated MTA2 (2.5-fold) and smoothened homolog (SMO, 4.5-fold). Figure $3 \mathrm{a}$ shows the functional relationship network of a selection of DEGs relating to lipid metabolism $(P<0.01)$. expression, with a stringency $\geq \pm 1.5$-fold change for the comparisons control versus diet $A$; control versus diet $B$, and diet $B$ versus diet $C$. b Depicts the effect of dietary manipulation on the expression of genes involved in liver damage/regeneration, angiogenesis, fibrosis, inflammation, and proliferation $(P<0.01)$

Taken together, these results suggest that the Trans-fat/ HFCS diet reduced hepatic lipogenesis and upregulated the expression of genes relating to hepatic lipid metabolism, fibrosis, angiogenesis, and inflammation compared to control. 


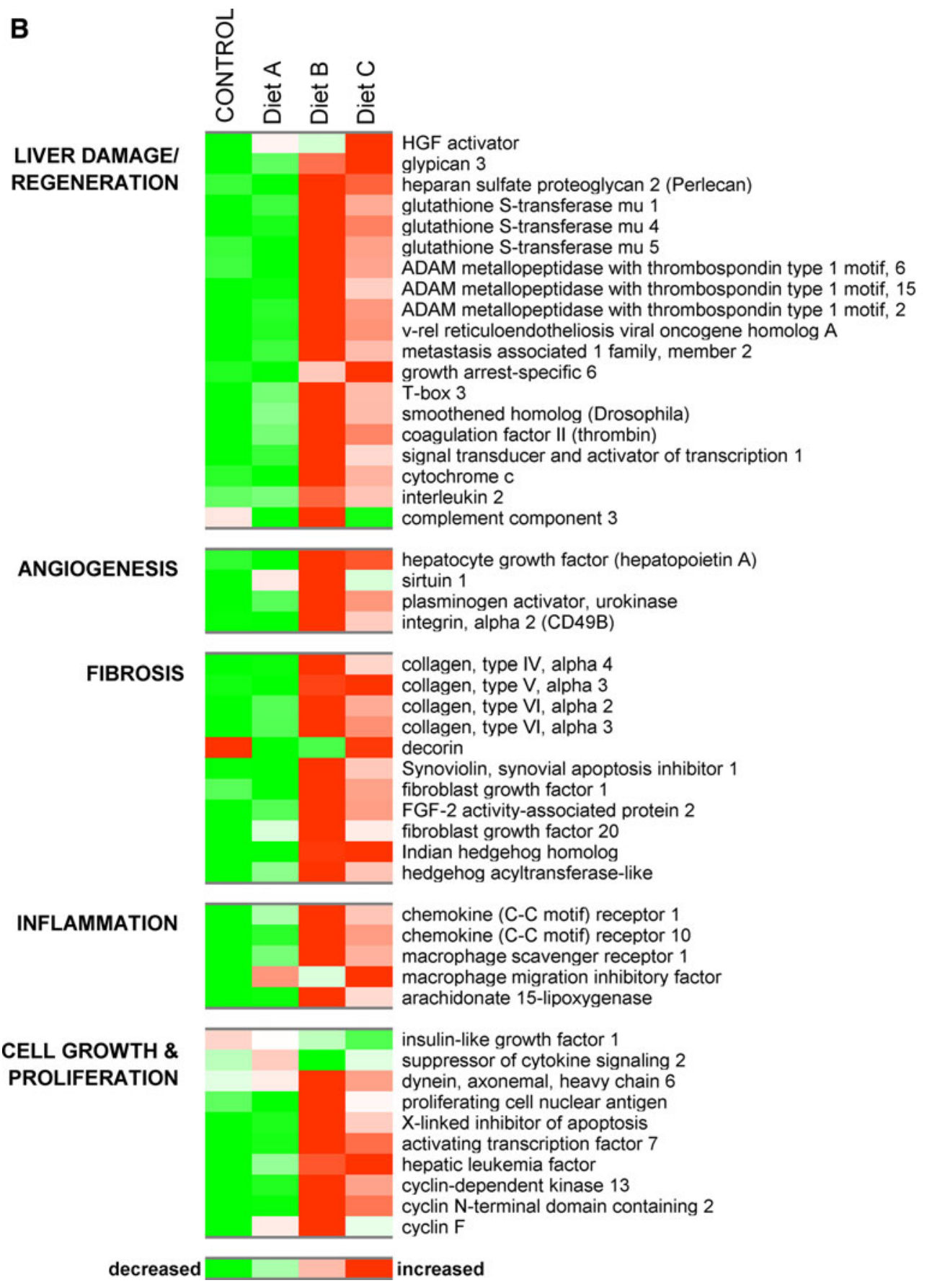

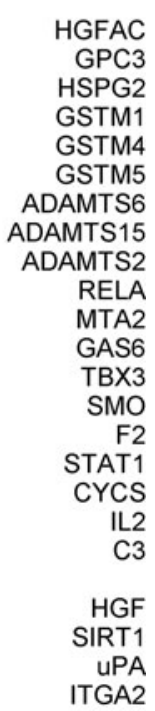

COL4A4

COL5A3

COL6A2

COL6A3

DCN

SYVN1

FGF1

GAFA2

FGF20

IHH

HHATL

CCR1

CCR10

MSR1

MIF

ALOX15

IGF1

SOCS2

DNAH6

PCNA

XIAP

ATF7

HLF

CDK13

CNTD2

CCNF

Fig. 2 continued

Monosodium glutamate consumption alters feline hepatic gene transcription

A completely different pattern of gene expression was apparent in the livers of MSG diet A animals, who also had elevated levels of hepatic TAG, serum insulin, and HOMAIR. 2-way ANOVA analysis revealed a subset of 680 hepatic DEGs (234 upregulated and 446 downregulated), which were responsive to dietary MSG compared to control diet. The expression of glyceroneogenic DEGs including diacylglycerol acyltransferase (DGAT1) and acylglycerolphosphate acyltransferase 9 (AGPAT9) levels was both upregulated 1.8-fold (Fig. 2). Glycerol kinase, which converts glycerol to glycerol-3-phosphate, the first substrate in the glycerol phosphate pathway for de novo TAG synthesis was also modestly (1.5-fold) upregulated in the MSG diet group compared to control. PCK1, an enzyme which converts oxaloacetate into phosphoenolpyruvate, 


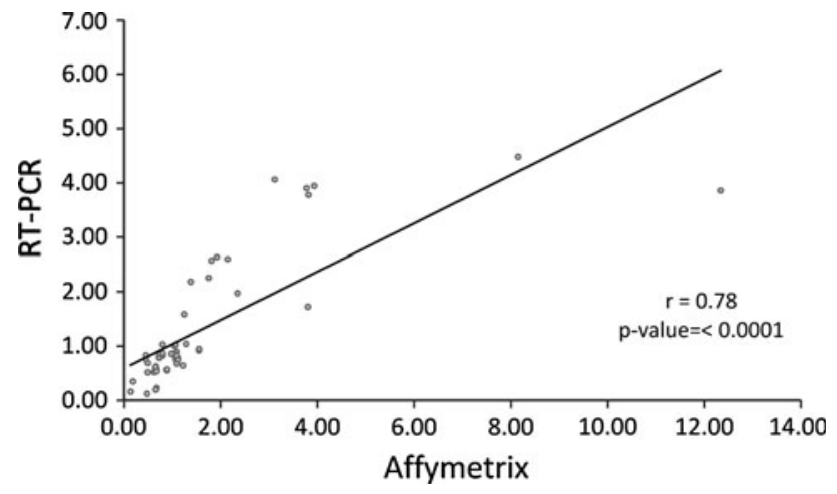

Fig. 3 Correlation of the ratios from the microarray and real-time PCR data set. Genes that differed significantly $(P<0.01)$ in their regulation between the diet groups' microarray analysis were selected and validated with the same samples by real-time PCR analysis. Ratios of expressions between the diet comparisons calculated from the microarray data set correlated well with the ratio calculated from the real-time PCR data $(r=0.78, P<0.0001)$

was upregulated 1.8-fold, further suggestive of glyceroneogenesis in this diet group. Genes associated with lipid mobilization and storage, such as perilipin 2 and fatty acid binding protein 1 were upregulated 2- and 1.7-fold compared to control. A number of lipolytic DEGs were also upregulated in the livers of MSG diet cats, including carnitine palmitoyltransferase 1A (PLT1A; 3.8-fold), acylCoA dehydrogenase (ACAD11; 2.3-fold) hydroxysteroid (17-beta) dehydrogenase 2 (HSD17B2; 2.8 -fold). However, expression levels of lipogenic transcription factor SREBP1 were unchanged in MSG diet cats compared to control, and other lipogenic genes such as ACLY, FAS, and HMGCR were slightly decreased, suggesting an inhibition in the pathway converting citrate into palmitoyl-CoA in MSG cats. MSG also doubled the expression of socs2 (suppressor of cytokine signaling 2) while halving IGF-1 expression, suggestive of impairment in the growth hormone axis.

MSG alters Trans-fat/HFCS-induced hepatic gene expression

In order to see how MSG could modify the Trans-fat/ HFCS-induced gene expression profile, we next identified a subset of 803 DEGs (345 upregulated and 458 downregulated), which showed significant changes in expression in the comparison of gene expression in the livers of diet $\mathrm{C}$ versus diet $\mathrm{B}$ cats. diet $\mathrm{C}$ further increased the expression levels of glyceroneogenic DEGs DGAT1, glycerol kinase (GK), AGPAT9, and PCK1 compared to control or diet B cats (Fig. 2). Genes associated with cholesterol metabolism were also upregulated in the $\operatorname{diet} \mathrm{C}$ animals including Cyp7a1, ABCC3, and ABCG8, which were increased 3-, 2.8-, and 2.3-fold over levels in diet B livers, respectively.
SPEBF1 levels in the group $\mathrm{C}$ cats were 2.8-fold higher than group B, whereas expression of lipogenic FAS and ACLY was similar to those in diet group B. Interestingly, the expression of proliferation genes PCNA and XIAP was each reduced 3- and 2-fold compared to levels in diet group $\mathrm{B}$, reducing them to control levels.

Confirmation of the microarray data using RT-PCR of feline mRNA

We performed RT-PCR on the pooled feline livers from the 4 diet groups, using primers designed from previously published sequences of ten Felis catus mRNAs, selected for biological relevance from the list of DEGs obtained from our microarray analysis. Table 2 indicated the accession number and sequence of these feline mRNAs. Pearson correlation coefficients between the microarray analysis and qRT-PCR were calculated. Ratios of expressions between the diet comparisons calculated from the microarray data set correlated well with the ratio calculated from the real-time PCR data (Fig. 3, $r=0.78, P<0.0001$ ).

Gene function ontology and interaction network analysis

The function ontology analysis of deregulated genes for specific diet comparisons was performed using the Ingenuity Knowledge Base. The biological functions assigned to the data set were ranked by significance $(-\log P$ value). Figure 4 shows the relevant biological function and toxicity analysis categories enriched by the data sets for the comparisons of interest [A] diet A versus control, [B] diet $\mathrm{B}$ versus control, and $[\mathrm{C}] \operatorname{diet} \mathrm{C}$ versus diet $\mathrm{B}$. The most noteworthy cellular and molecular biological functions associated with the patterns of gene expression within these comparisons included lipid metabolism, cell-to-cell signaling, and tissue development (Fig. 4a). Deregulated toxicological categories included liver fibrosis, cirrhosis, and proliferation (Fig. 4b). Figure 5 shows graphical mapping and cellular location of a network of biologically relevant genes deregulated by diet, relating to hepatic steatosis and metabolic deregulation. Noteworthy, focus genes in this network included cell growth and proliferation gene MYC, the lipid-regulating transcription factor Srebf1, hepatocyte nuclear factor $4 \mathrm{a}$ (Hnf4a), and hepatocyte growth factor.

\section{Discussion}

The present results suggest that dietary manipulation prenatally and over the 9 months of life can markedly affect feline physiology and hepatic gene expression. The 
Fig. 4 Bar chart represents the most significant biological functions (a) and toxicology analysis (b) of genes deregulated by diet for comparisons control versus diet A (red bars), control versus diet $\mathrm{B}$ (blue bars), and diet $\mathrm{C}$ versus diet B (green bars). $x$-axis represents- $\log$ of the $P$ value denoting significance
A

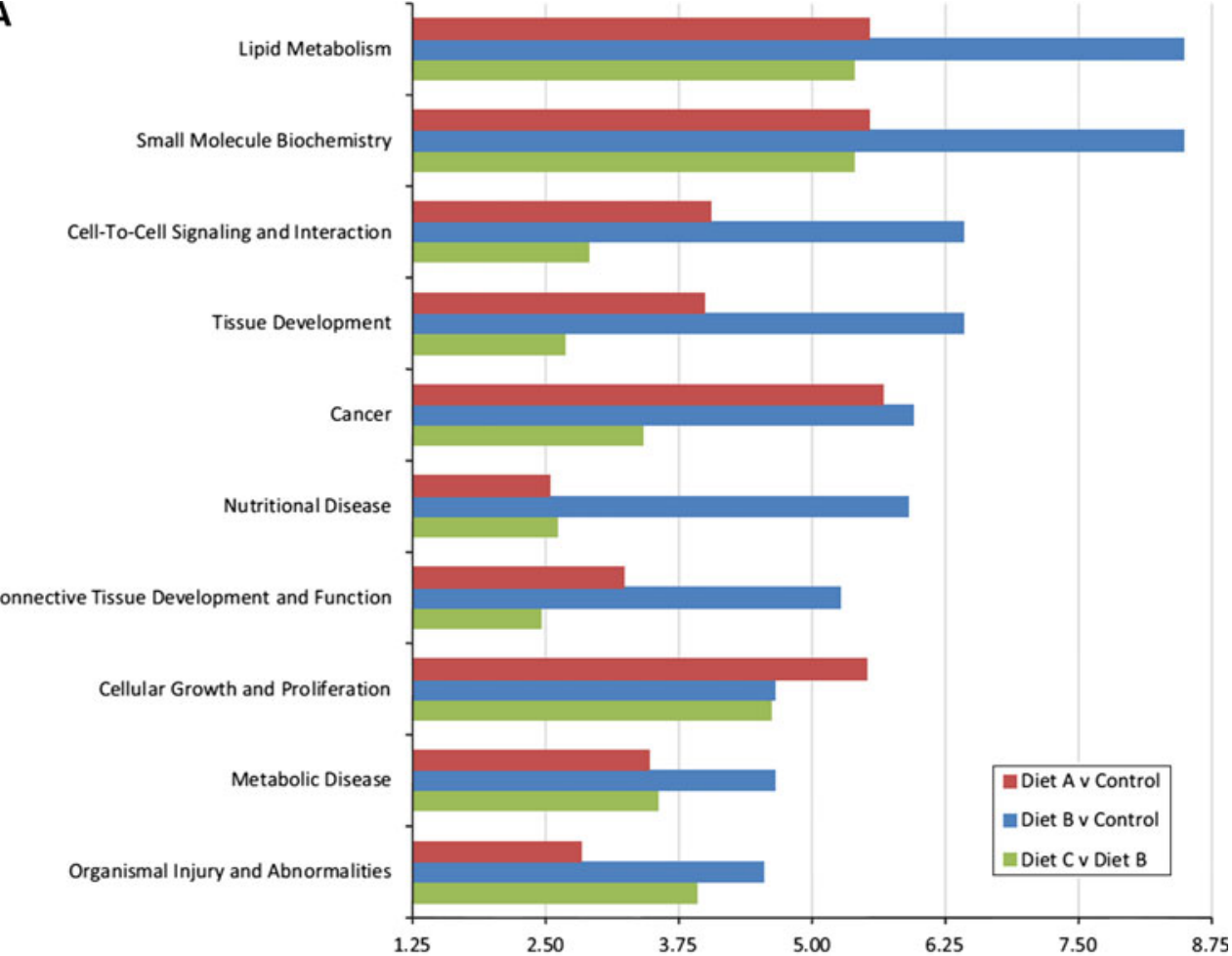

B

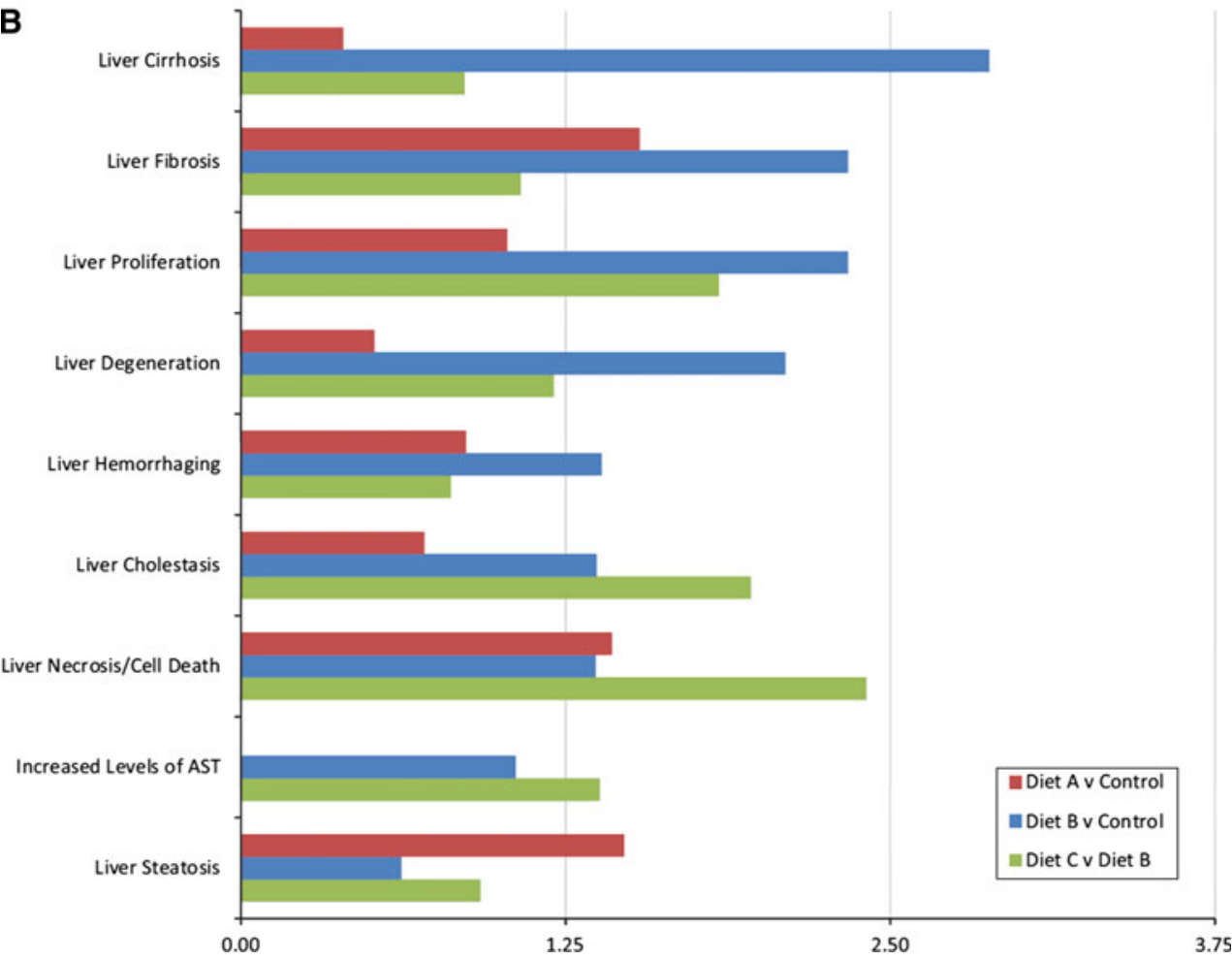

prevalence of obesity has increased in the human population over recent decades, and a similar increase has been observed in cats (German 2006). In humans, obesity is strongly associated with fatty liver disease that has been extensively studied in various rodent models of diet- induced NAFLD (Collison et al. 2009a, 2010). Simple fatty liver disease is usually a benign condition; however, some individuals develop a progressively severe pathology involving fibrosis, inflammation, and cirrhosis, and the reason for this is not fully understood (Wouters et al. 


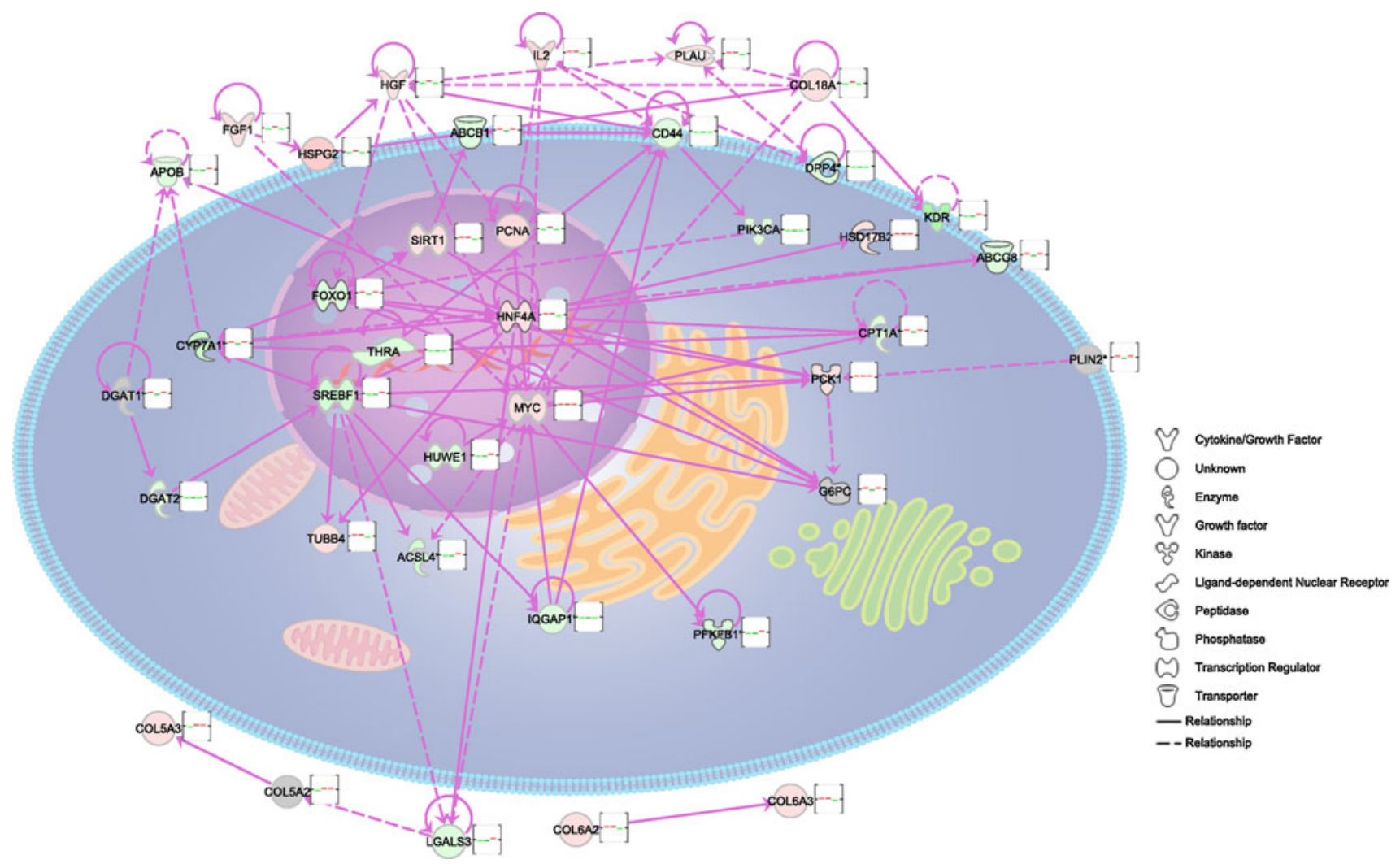

Fig. 5 Ingenuity pathway analysis was used to create a network of biologically relevant genes regulated in response to diet for comparisons control versus diet $\mathrm{A}$, control versus $\operatorname{diet} \mathrm{B}$, and $\operatorname{diet} \mathrm{C}$ versus diet B. The network is displayed graphically as nodes representing genes and edges (the biological relationship between the genes).
Different shaped nodes represent the functional class of the gene product. The position of the node represents the subcellular localization of the gene product. A total of 38 genes were represented in the network, with a number of focus genes with functions relating to transcription, growth and proliferation, and lipid metabolism
2008). Rodent models of diet-induced steatohepatitis and hepatic fibrosis have been disappointing up till now for a number of reasons (Larter and Yeh 2008; Anstee and Goldin 2006; Ogasawara et al. 2011). It could be that exposure to the dietary risk factor was insufficient to induce progressive disease in these models; or that commonly studied strains of rodents such as $\mathrm{C} 57 \mathrm{BL} / 6 \mathrm{~J}$ mice lack the genetic factors required for susceptibility to fibrotic and cirrhotic damage. Animal models which more closely resembled human pathology with respect to NAFLD and NASH would be desirable, particularly in relation to gene expression modulation (nutrigenomics), which could become targets for therapeutic intervention in hepatic fibrosis and tissue damage. Since maternal nutrition during pregnancy affects many aspects of physiology and development of the offspring, including liver function (Chapman et al. 2000), our model of diet-induced hepatic steatosis involved life-time exposure to the diets beginning in utero in order to mimic more closely the human situation. This manuscript describes a novel model using four different diet regimens that produced significant changes in the extent of hepatic steatosis and markers of fibrosis and liver damage between the study groups, together with significant changes in the expression of hepatic genes involved in lipid metabolism, fibrosis, inflammation, and tissue damage/ remodeling.

Interestingly, Trans-fat/HFCS-fed cats in diet groups B and $\mathrm{C}$ had similar levels of body fat to those of control diet cats, and none of the diets resulted in hyperphagia. It has previously been shown that unlike rodents, cats are able to maintain body weight when allowed ad libitum access to palatable high-fat diets (Bradshaw et al. 1996); and it has been suggested that part of the mechanism by which this occurs is via an increase in fatty acid oxidation (Lester et al. 1999). In support of these observations, we found that levels of hepatic transcription factor PPAR delta, implicated in promoting fatty acid catabolism (Cao et al. 2010), were increased in cats in diet groups B and C. In order for beta-oxidation to commence, fatty acids must first be activated by an acyl-CoA synthetase that uses ATP to produce a reactive acyl adenylate, and we also found that several Acyl-CoA synthetases were upregulated in both these diet groups. Further hints at a mechanism, whereby our cats were able to maintain normal body weight and 
lipid profile while consuming a diet enriched for Trans-fat/ HFCS is provided by the fact that the expression of lipogenic genes such as FAS and ACLY, together with major lipogenic transcription factor SREBP1C (Guillou et al. 2008), were robustly downregulated in the livers of these animals. We also noted that the expression of genes involved in bile acid synthesis and efflux (Erickson et al. 2003) for example Cyp7a1, ABCG8, ABCC3/MRP3, cholesterol uptake (LDLR), transport (ApoB), and de novo cholesterol synthesis (HMGCR, HMGCS1) were all reduced in cats fed the Trans-fat/HFCS diet, and this may explain why these cats did not exhibit increased levels of serum cholesterol and hepatic TAG compared to control.

It has previously been suggested that hepatic enzymes in the cat are not particularly responsive to different dietary treatments (Rogers and Morris 1977), and a separate study indicated that blood glucose levels failed to rise significantly in cats reared on various sugar and glucose diets compared to controls (Drochner and Muller-Schlosser 2008). We found evidence of modest upregulation of hepatic genes involved in glycolysis and fructolysis in cats reared on the Trans-fat/HFCS diet, which did not appear to be sufficient to increase the hepatic TAG content in these animals. Conversely, accompanying the changes in the expression of genes involved in lipid metabolism, we noted an increase in the appearance of fibrotic deposits in cats fed the Trans-fat/HFCS diets. It has recently been shown that fructose and Trans-fat feeding in rodents promote the development of NASH together with fibrosis (Tetri et al. 2008; Kohli et al. 2010); and indeed, increased fibrosis has also been associated with human fructose consumption in patients with NAFLD (Abdelmalek et al. 2010), similar to our present findings in cats. The proposed mechanism of this fructose-induced fibrosis is believed to occur via increased production of reactive oxygen species (ROS) and macrocytic infiltration, and we have previously shown that HFCS increases ROS activation in vitro, which could be attenuated by the antioxidant epigallocatechin gallate (Collison et al. 2009b). Trans-fat/HFCS-containing diets also increased the expression of a number of pro-inflammatory feline genes including Alox15, the gene encoding for 12/15-lipoxygenase (12/15-LO), which we have previously found to be upregulated in the adipose tissue of high fructose-fed mice (Collison et al. 2010). Targeted disruption of Alox 15 protects hyperlipidemic mice from hepatic steatosis (Martínez-Clemente et al. 2010) and reduces the expression of inflammatory markers and chemoattractants associated with inflammatory cell infiltration, further indicative of a role for Alox15 in promoting hepatic inflammation. Additionally, we found an increase in the expression of chemokine ( $\mathrm{C}-\mathrm{C}$ motif) receptor 1 (CCR1), which has previously been shown to promote hepatic fibrosis (Seki et al. 2009), and macrophage scavenger receptor 1(MSR1), indicative of macrophage infiltration. Fibrosis develops in response to chronic liver injury and is associated with an increase in the expression of hepatocyte growth factor (HGF) (Cramer et al. 2004), which we also found to be upregulated in animals exposed to Trans-fat/ HFCS. Hedgehog (Hh) ligand Indian Hh (Ihh), previously shown to be upregulated during hepatic fibrogenesis (Jung et al. 2010), was also increased in diet B cats. The increase in HGF was accompanied by elevations in urokinase plasminogen activator (uPA) and proliferating cell nuclear antigen (PCNA), suggestive of an upregulation of genes involved in cellular regeneration in these felines. Moreover, the livers of these animals also exhibited increased expression of genes that have been shown to be upregulated in human hepatocellular carcinoma, including RelA (Tai et al. 2000), glypican 3 (Wang et al. 2010), and perlecan (Tátrai et al. 2010).

The livers of cats in the MSG diet group A exhibited steatosis, which was accompanied by elevated fasting serum insulin and HOMA-IR levels. Insulin induces the expression of Socs2, a negative regulator of IGF1-related growth control (Greenhalgh et al. 2002), and MSG diet cats exhibited a doubling in the expression of Socs2 together with a halving of the expression of IGF1, indicating the possibility of disruption of the growth hormone action in these animals. This would tend to support previous observations that MSG induces growth hormone perturbations in rodents (Hermanussen and Tresguerres 2003; RomanRamos et al. 2011), accompanied by a reduction in serum IGF1 (Alponti et al. 2011; Fernandez-Tresguerres 2005). IGF1 is derived mainly from the liver, and low serum IGF1 is associated with increased human hepatic steatosis (Völzke et al. 2009). Diet A cat livers had increased expression of a number of genes related to hepatic steatosis, including DGAT1 (Millar et al. 2006), perlipin (Fujii et al. 2009), and fatty acid-binding protein 1. Interestingly, glycerol kinase expression was also upregulated in the livers of both MSG-containing diet groups A and C; and increased glycerol reutilization has previously been noted in the adipose tissue of MSG-treated rats (Dolnikoff et al. 2001), where enhanced glycerol utilization has been suggested to contribute to the development of obesity in these animals. Glycerol can also provide a substrate for de novo hepatic TAG synthesis, during which glycerol kinase is required to convert glycerol into glycerol-3-phosphate for subsequent esterification into TAG. Taken together, our data suggest that MSG may elevate hepatic TAG via a mechanism that includes disruption of hepatic Socs2/IGF1 regulation and upregulation of steatogenic gene expression.

A combination of all 3 dietary manipulations (Trans-fat/ HFCS and MSG: diet C) resulted in a histological phenotype similar to the livers of Trans-fat/HFCS-fed animals, and significantly elevated hepatic TG content compared to 
that of diet B cats, together with elevated serum cortisol levels possibly suggestive of increased physiological stress (Carlstead et al. 1993). Expression profile analysis revealed that diet $\mathrm{C}$ animals had a similar pattern of gene expression to that of diet $\mathrm{B}$; however, some gluconeogenic genes were upregulated and the expression of a number of lipid storage genes was also modulated. Beyond the identification of individual hepatic genes affected by diet, our analysis focused on the characterization of biological functions associated with genes modulated by diet. Gene function ontology analysis suggested that the Trans-fat and HFCS diet most strongly deregulated the expression of genes relating to lipid metabolism. Our study concluded when the animals reached nine months of age. It is possible that more significant changes in gene expression might have emerged if exposure to the diets had continued for a longer period of time.

In summary, our data suggest that exposure to dietary MSG in utero and throughout the first 9 months of life may increase body fat, hepatic steatosis, and insulin deregulation compared to control. Conversely, exposure to dietary Trans-fat/HFCS promoted hepatic fibrosis and markers of heptocellular injury. Our microarray analysis of hepatic gene expression in these 4 groups of animals indicated deregulation of genes involved in hepatic lipogenesis, lipolysis, cholesterol metabolism, fibrosis, liver damage, and tissue regeneration, consistent with the phenotypes we observed. A further outcome from the present study is that these dietary manipulations may possibly have shed light on the nature of the genes involved in the induction of simple steatosis as compared to hepatic fibrosis, in this feline model. We therefore suggest that our experimental model of diet-induced hepatic steatosis is compatible with the use of Felis catus as model for mammalian metabolism in hepatic steatosis.

Acknowledgments We thank Razan Bakheet and Rhea Mondreal for excellent technical assistance. Our gratitude goes to Mr Hakim AlEnazi for his unparalleled help in coordinating research resources. This research received no specific grant from any funding agency in the public, commercial, or not-for-profit sectors.

Conflict of interest The authors declare that they have no conflict of interest.

\section{References}

Abdelmalek MF, Suzuk A, Guy C, Unalp-Arida A, Colvin R, Johnson RJ, Diehl AM (2010) Nonalcoholic steatohepatitis clinical research network. Increased fructose consumption is associated with fibrosis severity in patients with nonalcoholic fatty liver disease. Hepatology 51(6):1961-1971

Adams LA, Lindor KD (2007) Nonalcoholic fatty liver disease. Ann Epidemiol 17(11):863-869
Alponti RF, Frezzatti R, Barone JM, Alegre Vde S, Silveira PF (2011) Dipeptidyl peptidase IV in the hypothalamus and hippocampus of monosodium glutamate obese and food-deprived rats. Metabolism 60(2):234-242

Anstee QM, Goldin RD (2006) Mouse models in non-alcoholic fatty liver disease and steatohepatitis research. Int $\mathbf{J}$ Exp Pathol 87:1-16

Armitage JA, Khan IY, Taylor PD, Nathanielsz PW, Poston L (2004) Developmental programming of metabolic syndrome by maternal nutritional imbalance; how strong is the evidence from experimental models in animals. J Physiol 561:355-377

Bellentani S, Saccoccio G, Masutti F, Crocè LS, Brandi G, Sasso F, Cristanini G, Tiribelli C (2000) Prevalence of and risk factors for hepatic steatosis in Northern Italy. Ann Intern Med 132:112-117

Bradshaw JWS, Goodwin D, Legrand-Defretin V, Nott HM (1996) Food selection by the domestic cat, an obligate carnivore. Comp Biochem Physiol A Physiol 114:205-209

Cao A, Li H, Zhou Y, Wu M, Liu J (2010) Long chain acyl-CoA synthetase-3 is a molecular target for peroxisome proliferatoractivated receptor delta in HepG2 hepatoma cells. J Biol Chem 285(22):16664-16674

Carlstead K, Brown JL, Strawn W (1993) Behavioral and physiological correlates of stress in laboratory cats. Appl Anim Behav Sci 38:143-158

Chapman C, Morgan LM, Murphy MC (2000) Maternal and early dietary fatty acid intake: changes in lipid metabolism and liver enzymes in adult rats. J Nutr 130(2):146-151

Collison KS, Maqbool Z, Saleh SM, Inglis A, Makhoul NJ, Bakheet R, Al-Johi M, Al-Rabiah R, Zaidi MZ, Al-Mohanna FA (2009a) Effect of dietary monosodium glutamate on Trans-fat-induced nonalcoholic fatty liver disease. J Lipid Res 50(8):1521-1537

Collison KS, Saleh SM, Bakheet RH, Al-Rabiah RK, Inglis AL, Makhoul NJ, Maqbool ZM, Zaidi MZ, Al-Johi MA, Al-Mohanna FA (2009b) Diabetes of the liver: the link between nonalcoholic fatty liver disease and HFCS-55. Obesity (Spiver Spring) 17(11):2003-2013

Collison KS, Maqbool ZM, Inglis AL, Makhoul NJ, Saleh SM, Bakheet RH, Al-Johi M, Al-Rabiah R, Zaidi MZ, Al-Mohanna FA (2010) Effect of dietary monosodium glutamate on HFCSinduced hepatic steatosis: expression profiles in the liver and visceral fat. Obesity (Silver Spring) 18(6):1122-1134

Collison KS, Zaidi MZ, Saleh SM, Inglis A, Mondreal R, Makhoul NJ, Bakheet R, Burrows J, Milgram NW, Al-Mohanna FA (2011) Effect of trans-fat, fructose and monosodium glutamate feeding on feline weight gain, adiposity, insulin sensitivity, adipokine and lipid profile. Br J Nutr 24:1-10 (Epub ahead of print)

Cramer T, Schuppan D, Bauer M, Strefeld T, Hahn EG, Herbst H (2004) Hepatocyte growth factor and c-Met expression in rat and human liver fibrosis. Liver Int 24:335-344

Crystal MA, Norsworthy GD (2007) In: Crystal MA, Grace SF, Tilley LP (eds) The feline patient, vol 1, 3rd edn. Wiley-Blackwell, ISBN-10: 0781762685

De Campos KE, Sinzato YK, Pimenta Wde P, Rudge MV, Damasceno DC (2007) Effect of maternal obesity on diabetes development in adult rat offspring. Life Sci 81(19-20):14731478

Diniz YS, Faine LA, Galhardi CM, Rodrigues HG, Ebaid GX, Burneiko RC, Cicogna AC, Novelli EL (2005) Monosodium glutamate in standard and high-fiber diets: metabolic syndrome and oxidative stress in rats. Nutrition 21(6):749-755

Dolnikoff M, Martin-Hidalgo A, Machado UF, Lima FB (2001) Herrera E (2001) Decreased lipolysis and enhanced glucose utilization by adipose tissue prior to development of obesity in monosodium glutamate (MSG) treated rats. Int $\mathrm{J}$ Obesity 25:426-443 
Dowling RJ, Bienzle D (2005) Gene-expression changes induced by Feline immunodeficiency virus infection differ in epithelial cells and lymphocytes. J Gen Virol 86(Pt 8):2239-2248

Drochner W, Muller-Schlosser S (2008) Tolerance of various sugars in cats. In: Anderson RS (ed) Nutrition of the dog and cat. Pergammon press, Toronto, pp 101-111

Erickson SK, Lear SR, Deane S, Dubrac S, Huling SL, Nguyen L, Bollineni JS, Shefer S, Hyogo H, Cohen DE, Shneider B, Sehayek E, Ananthanarayanan M, Balasubramaniyan N, Suchy FJ, Batta AK, Salen G (2003) Hypercholesterolemia and changes in lipid and bile acid metabolism in male and female cyp7A1deficient mice. J Lipid Res 44(5):1001-1009

Fernandez-Tresguerres HJA (2005) Effect of monosodium glutamate given orally on appetite control (a new theory for the obesity epidemic). An R Acad Nac Med (Madr) 122(2):341-355

Fujii H, Ikura Y, Arimoto J, Sugioka K, Iezzoni JC, Park SH, Naruko T, Itabe H, Kawada N, Caldwell SH, Ueda M (2009) xpression of perilipin and adipophilin in nonalcoholic fatty liver disease; relevance to oxidative injury and hepatocyte ballooning. J Atheroscler Thromb 16(6):893-901

German AJ (2006) The growing problem of obesity in dogs and cats. J Nutr 136(7 Suppl):1940S-1946S

Greenhalgh CJ, Bertolino P, Asa Sl, Metcalf D, Corbin JE, Adams TE, Davey HW, Nicola NA, Hilton DJ, Alexander WS (2002) Growth enhancement in suppressor of cytokine signaling 2 (SOCS-2)-deficient mice is dependent on signal transducer and activator of transcription 5b (STAT5b). Mol Endocrinol 16(6):1394-1406

Guillou H, Martin PG, Pineau T (2008) Transcriptional regulation of hepatic fatty acid metabolism. Subcell Biochem 49:3-47

Henson MS, O'Brien TD (2006) Feline models of type 2 diabetes mellitus. ILAR J 47(3):234-242

Hermanussen M, Tresguerres JA (2003) Does high glutamate intake cause obesity? J Pediatr Endocrinol Metab 16(7):965-968

Hirata AE, Andrade IS, Vaskevicius P, Dolnikoff MS (1997) Monosodium glutamate (MSG)-obese rats develop glucose intolerance and insulin resistance to peripheral glucose uptake. Braz J Med Biol Res 30(5):671-674

Hoenig M (2002) Comparative aspects of diabetes mellitus in dogs and cats. Mol Cell Endocrinol 197(1-2):221-229

Hoenig M (2006) The cat as a model for human nutrition and disease. Curr Opin Clin Nutr Metab Care 9(5):584-588

Ibrahim WH, Bailey N, Sunvold GD, Bruckner GG (2003) Effects of carnitine and taurine on fatty acid metabolism and lipid accumulation in the liver of cats during weight gain and weight loss. Am J Vet Res 64(10):1265-1277

Jung Y, Witek RP, Syn WK, Choi SS, Omenetti A, Premont R, Guy CD, Diehl AM (2010) Signals from dying hepatocytes trigger growth of liver progenitors. Gut 59(5):655-665

Kohli R, Kirby M, Xanthakos SA, Softic S, Feldstein AE, Saxena V, Tang PH, Miles L, Miles MV, Balistreri WF, Woods SC, Seeley RJ (2010) High-fructose, medium chain Trans-fat diet induces liver fibrosis and elevates plasma coenzyme Q9 in a novel murine model of obesity and nonalcoholic steatohepatitis. Hepatology 52(3):934-944

Laflamme DP (2007) Five minute veterinary consult: canine and feline. In: Obesity, pp 982-983. Blackwell, Ames

Larter CZ, Yeh MM (2008) Animal models of NASH: getting both pathology and metabolic context right. J Gastroenterol Hepatol 23(11):1635-1648

Lê KA, Bortolotti M (2008) Role of dietary carbohydrates and macronutrients in the pathogenesis of nonalcoholic fatty liver disease. Curr Opin Clin Nutr Metab Care 11(4):477-482

Lester T, Czarnecki-Maulden G, Lewis D (1999) Cats increase fatty acid oxidation when isocalorically fed meat-based diets with increasing fat content. Am J Physiol 277(3 Pt 2):R878-R886
Martínez-Clemente M, Ferré N, Titos E, Horrillo R, González-Périz A, Morán-Salvador E, López-Vicario C, Miquel R, Arroyo V, Funk CD, Clària J (2010) Disruption of the 12/15-lipoxygenase gene (Alox15) protects hyperlipidemic mice from nonalcoholic fatty liver disease. Hepatology 52(6):1980-1991

Matthews DR, Hosker JP, Rudenski AS (1985) Homeostasis model assessment: insulin resistance and $\beta$-cell function from fasting plasma glucose and insulin concentrations in man. Diabetologia 28:412-419

Matyšková R (2008) Comparison of the obesity phenotypes related to monosodium glutamate effect on arcuate nucleus and/or the high fat diet feeding in C57Bl/6 and NMRI mice. Physiol Res 57(5):727-734

Millar JS, Stone SJ, Tietge UJ, Tow B, Billheimer JT, Wong JS, Hamilton RL, Farese RV Jr, Rader DJ (2006) Short-term overexpression of DGAT1 or DGAT2 increases hepatic triglyceride but not VLDL triglyceride or apoB production. J Lipid Res 47(10):2297-2305

Minor RK, López M, Younts CM, Jones B, Pearson KJ, Michael Anson R, Diéguez C, de Cabo R (2011) The arcuate nucleus and neuropeptide $\mathrm{Y}$ contribute to the antitumorigenic effect of calorie restriction. Aging Cell 10(3):483-492

Nakanishi Y, Tsuneyama K, Fujimoto M, Salunga TL, Nomoto K, An JL, Takano Y, Iizuka S, Nagata M, Suzuki W, Shimada T, Aburada M, Nakano M, Selmi C, Gershwin ME (2008) Monosodium glutamate (MSG): a villain and promoter of liver inflammation and dysplasia. J Autoimmunol 30(1-2):42-50

Nemeroff CB, Lipton MA, Kizer JS (1978) Models of neuroendocrine regulation: use of monosodium glutamate as an investigational tool. Dev Neurosci 1(2):102-109

Nishimura Y, Miyazawa T, Ikeda Y, Izumiya Y, Nakamura K, Cai JS, Sato E, Kohmoto M, Mikami T (1998) Molecular cloning and sequencing of feline stromal cell-derived factor- $1 \alpha$ and $\beta$. Eur $\mathrm{J}$ Immunogenet 25:303-305

Ogasawara M, Hirose A, Ono M, Aritake K, Nozaki Y, Takahashi M, Okamoto N, Sakamoto S, Iwasaki S, Asanuma T, Taniguchi T, Urade Y, Onishi S, Saibara T, Oben JA (2011) A novel and comprehensive mouse model of human non-alcoholic steatohepatitis with the full range of dysmetabolic and histological abnormalities induced by gold thioglucose and a high-fat diet. Liver Int 31(4):542-551

Ritchey JW, Levy JK, Bliss SK, Tompkins WA, Tompkins MB (2001) Constitutive expression of types 1 and 2 cytokines by alveolar macrophages from feline immunodeficiency virusinfected cats. Vet Immunol Immunopathol 79:83-100

Rogers QR, Morris JG (1977) Lack of hepatic enzyme adaption to low and high levels of dietary protein in the adult cat. Enzyme 22:348-356

Roman-Ramos R, Almanza-Perez JC, Garcia-Macedo R, BlancasFlores G, Fortis-Barrera A, Jasso EI, Garcia-Lorenzana M, Campos-Sepulveda AE, Cruz M, Alarcon-Aguilar FJ (2011) Monosodium glutamate neonatal intoxication associated with obesity in adult stage is characterized by chronic inflammation and increased mRNA expression of peroxisome proliferatoractivated receptors in mice. Basic Clin Pharmacol Toxicol 108(6):406-413

Sasaki Y, Suzuki W, Shimada T, lizuka S, Nakamura S, Nagata M, Fujimoto M, Tsuneyama K, Hokao R, Miyamoto K, Aburada M (2009) Dose dependent development of diabetes mellitus and non-alcoholic steatohepatitis in monosodium glutamate-induced obese mice. Life Sci 85(13-14):490-498

Seki E, De Minicis S, Gwak GY, Kluwe J, Inokuchi S, Bursill CA, Llovet JM, Brenner D, Schwabe RF (2009) CCR1 and CCR5 promote hepatic fibrosis in mice. J Clin Invest 119(7):1858-1870

Tai DI, Tsai SL, Chang YH, Huang SN, Chen TC, Chang KS, Liaw YF (2000) Constitutive activation of nuclear factor kappaB in hepatocellular carcinoma. Cancer 89(11):2274-2281 
Tanaka K, Shimada M, Nakao K, Kosugi A, Yamamoto H, Oya N (1983) Effects of excess amounts of synthetic amino acid preparations on hypothalamus of mice and kittens. Biol Neonate 43(1-2):72-79

Tátrai P, Egedi K, Somorácz A, van Kuppevelt TH, Ten Dam G, Lyon M, Deakin JA, Kiss A, Schaff Z, Kovalszky I (2010) Quantitative and qualitative alterations of heparan sulfate in fibrogenic liver diseases and hepatocellular cancer. J Histochem Cytochem 58(5):429-441

Tetri LH, Basaranoglu M, Brunt EM, Yerian LM, NeuschwanderTetri BA (2008) Severe NAFLD with hepatic necroinflammatory changes in mice fed Trans-fats and a high-fructose corn syrup equivalent. Am J Physiol Gastrointest Liver Physiol 295(5): G987-G995

Völzke H, Nauck M, Rettig R, Dörr M, Higham C, Brabant G, Wallaschofski H (2009) Association between hepatic steatosis and serum IGF1 and IGFBP-3 levels in a population-based sample. Eur J Endocrinol 161(5):705-713

Wang FH, Yip YC, Zhang M, Vong HT, Chan KI, Wai KC, Wen JM (2010) Diagnostic utility of glypican-3 for hepatocellular carcinoma on liver needle biopsy. J Clin Pathol 63(7):599-603

Wouters K, van Gorp PJ, Bieghs V, Gijbels MJ, Duimel H, Lütjohann D (2008) Dietary cholesterol, rather than liver steatosis, leads to hepatic inflammation in hyperlipidemic mouse models of nonalcoholic steatohepatitis. Hepatology 48(2):474-486

Youssef WI, McCullough AJ (2002) Steatohepatitis in obese individuals. Best Pract Res Clin Gastroenterol 16(5):733-747

Yu T, Zhao Y, Shi W, Ma R, Yu L (1997) Effect of maternal oral administration of monosodium glutamate at a late stage of pregnancy on developing mouse fetal brain. Brain Res 747:195-206 